\title{
Sustainable Development Study on an Energy-Economic-Environment System Based on a Vector Autoregression Model in Shanxi, China
}

\author{
Herui Cui, Ruirui Wu*, Tian Zhao \\ Department of Economics and Management, North China Electric Power University, \\ Baoding, Hebei, China
}

Received: 2 February 2018

Accepted: 27 March 2018

\begin{abstract}
The coordination of an energy-economic-environment (3E) system has attracted increasing attention recently to achieve sustainable development. Shanxi Province, a typical energy-dominated region in China, has long-term dependency on coal industry generating extensive economic growth, which is detrimental to sustainable progress. Therefore, it is beneficial to explore the intrinsic connection of the 3E system in Shanxi for policy implications. Based on energy consumption, GDP and energy-related $\mathrm{CO}_{2}$ emissions from 1999 to 2015, a VAR model of the 3E system in Shanxi was established. Impulse response analysis and variance decomposition were employed to analyze the dynamic relationship between energy, economy, and the environment, with these three values being predicted from 2016 to 2023. Results indicate that a positive shock in economic growth negatively impacts energy consumption, and a positive change in energy consumption positively affects economic growth and $\mathrm{CO}_{2}$ emissions as well. From variance decomposition, the innovation to energy consumption accounts for fluctuation of $82.29 \%$ in GDP in the long run, and $\mathrm{CO}_{2}$ emissions attributed to innovations in energy consumption range $64.53 \%$ to $77.68 \%$. VAR model forecasts there will be an increasing tendency of energy consumption, GDP, and $\mathrm{CO}_{2}$ emissions. Accordingly, Shanxi can achieve sustainable development through vigorously optimizing energy structure and promoting low-carbon technological innovation.
\end{abstract}

Keywords: sustainable development, energy-economic-environment (3E) system, VAR model, Shanxi

*e-mail: wrr20180131@163.com 


\section{Introduction}

The coordinated development of energy, economy, and the environment has become the focus of sustainable development in a country or region [1]. As the largest developing country, China has been experiencing rapid economic growth and the overuse of coal as a leading resource by the energy structure, which has been contributing to grievous global warming caused especially by $\mathrm{CO}_{2}$ emissions $[2,3]$. The traditional mode of extensive economic development has paid China a high cost of resource and environment issues. Meanwhile, China has now become the largest $\mathrm{CO}_{2}$ emitter in the world and joined the Paris Agreement for working together to cope with the "greenhouse effect" globally after 2020 [4]. This implies that the policy makers should implement a trade-off between economic steady development, efficient energy utilization, and $\mathrm{CO}_{2}$ emission reduction in regional development plans [5]. Therefore, it is imperative to probe how an energy-economic-environment (3E) system interacts and consequently investigate how to coordinate their developments [6].

Shanxi Province is a typical coal-related region and a significant energy and old industrial base in central China. Since the founding of the People's Republic of China, Shanxi has produced 15.3 billion tons of coal, accounting for one fourth of the national total [7], with the net amount of coal transferred being 10.4 billion tons and accounting for $3 / 4$ of the national total, and coke production and the amount of the transfer accounting for $40 \%$ and $60 \%$ of the national total respectively [8], making a tremendous contribution toward China's economic construction.

However, the long-term extensive economic development model in Shanxi has engendered excessive dependence on coal and a single industrial structure. The continuous exploitation of coal mines has caused the depletion of these resources and the formation of many subsidence and goaf areas. Meanwhile, the immoderate consumption of fossil fuels speeds up the growth of $\mathrm{CO}_{2}$ emissions and damages ecological environment, which in turn will hinder the sustainable development of Shanxi Province.

Currently, under the concept of "lucid waters and lush mountains" being invaluable assets and "transforming economic development" as proposed by the Chinese government, Shanxi has regulated the resources and environment, and the external and internal energy demand sides of this region have also changed accordingly. As a result, however, the profound economic contradictions in Shanxi have been thoroughly exposed, with economic growth having plummeted far below the national average level. Thus, the Thirteenth Five-year Plan for Economic and Social Development in Shanxi Province [9] clearly indicated that it is necessary to solve the major problem of "resource-based economic difficulties," achieving a remarkable enhancement in the level of green and low-carbon development. Given the severe situation of resources and environmental protection, it is consequential to investigate the development law and internal relations of the $3 \mathrm{E}$ system in Shanxi from a sustained development perspective, and then propose vigorous measures directed against coordinating process among energy, economy, and the environment, which has realistic meaning to accomplish in-depth reforms of a resource-based economy and green sustainable development in Shanxi Province.

The 3E model was first proposed in Japan with the aim of resolving the contradictions between energy, environment, and the economy [10]. Since the 1990s, the issue of coordinated and sustainable development of a $3 \mathrm{E}$ system has received increasing attention from domestic scholars in China, gradually forming relevant theoretical research framework, which has made some substantive progress. Research based on the $3 \mathrm{E}$ model in China can be generally classified as having national and provincial angles.

At the national level, the coordination degree of the $3 \mathrm{E}$ system based on the evaluation system method is usually expounded. Zhao [11] established a comprehensive evaluation system by measuring the comprehensive development level index of China's $3 \mathrm{E}$ subsystem and the coordination degree of the system, showing that the whole system was in weak coordination state and the contradiction between the three influenced the quality of sustainable development in China. Wang and Liu [12] developed the evaluation index system for the $3 \mathrm{E}$ system coordinating degree in China based on the AHP-GRAM model.

There is also plentiful research on the impact of policies on the economy, energy, and the environment. $\mathrm{Li}$ [13] used a $3 \mathrm{E}$ model to study development trends of the economy, energy, and environment before 2030. Yang and Jackson [14] explored the influence of China's coalbased methanol economy on energy and $\mathrm{CO}_{2}$ emissions. $\mathrm{Hu}$ et al. [5] analyzed the relationship between economic growth, power supply, energy conservation, and carbon emissions under China's low-carbon development. Tang et al. [15] pointed out dilemmas of the economy, energy, and the environment, concluding that sustainable development in China would have an impact on the global environment.

Some scholars have also discussed the 3E system in China from the dynamic angle. Han and Zhu [16] indicated there was a long-term cointegration relationship between energy consumption, GDP, and industrial sewage emissions by analysing China's 3E system. Liu [17] constructed a vector error correction model for China's $3 \mathrm{E}$ system, and found that there existed a longterm causal relationship between energy consumption and economic growth in China's $3 \mathrm{E}$ system.

Literature concerning the $3 \mathrm{E}$ system on a national level gave macro conclusions that were not applicable in all regions, with a noticeable diversity in economic development phases, natural conditions, resource endowment, and scientific and technological levels across every region throughout China. Thus scholars 
have continued to study more concretely on several representative provinces and cities.

Guan et al. [18] developed the regional 3E system, and obtained the coordinated form of different regions in China. Zuo et al. [19] probed in detail the long-term relationship of variables in the $3 \mathrm{E}$ system of the BeijingTianjin-Hebei Region. Zhao and Li [20] explored the overall level of the $3 \mathrm{E}$ system in the Inner Mongolia Autonomous Region under the 3E level evaluation system, finding the high speed of energy and economic system in contrast to the continuously receding level of environmental system development. Wang et al. [6] studied the coordination degree of the $3 \mathrm{E}$ system in Shandong Province, with the conclusion that the rapid economic development in Shandong accelerated energy consumption and reduced environmental quality. Liu and Zhou [21] calculated the coordinated development coefficient of Guangdong when establishing the $3 \mathrm{E}$ integration evaluation system. Jin et al. [22] researched the coupling mechanism of the $3 \mathrm{E}$ system in Shandong, and found that the coupling degree of the systems had been increasing year by year. Fu et al. [2] indicated the development of the Urumqi $3 \mathrm{E}$ system through the inexact multi-objective programming model.

Dominating Shanxi Province in terms of energy especially the coal industry, relevant studies concerning the comprehensive research on its $3 \mathrm{E}$ system are comparatively scant. Zhang [23] took advantage of the portfolio model to study the coordinated development of $3 \mathrm{E}$ in Shanxi, putting forward suggestions for the exploitation and utilization of coal. Zhang [24] analyzed the restrictive factors of low-carbon economy, and found that improving the efficiency of energy use and the proportion of clean energy can be the only way to sustainable development in Shanxi. Huang et al. [25] used a multivariate linear regression model to analyze the influence of energy consumption and environmental pollution on Shanxi's economic growth.

Shanxi is a national resource-based economy restructuring comprehensive reform pilot area in China. Reviewing existing literature, however, research conducted on 3E systems of economically backward resource-based areas represented by Shanxi Province is rare. Moreover, previous studies of the $3 \mathrm{E}$ system mainly emphasized qualitative analysis, and used aforementioned comprehensive evaluation models only considering the coordination degree or other indicators from a static point of view. Therefore, it is beneficial and necessary to analyze the intrinsic connection between energy, the economy, and the environment with a vector autoregression (VAR) model from a dynamic perspective. But to the authors' best knowledge, there is no previous work on this angle.

To make a contribution to filling in the gaps in existing studies, we conduct the paper from the following aspects. First, a VAR model is established for researching the $3 \mathrm{E}$ system in Shanxi Province, which is not subject to traditional economic theory and to avoid the estimated error caused by multicollinearity
[26]. Second, the relationship between the $3 \mathrm{E}$ system in Shanxi using impulse response analysis and variance decomposition is explored dynamically based on the VAR model, which can provide macroscopic decision-making for the local comprehensive balance and coordinated development of the three subsystems of energy, economy, and the environment. Finally, the utilization of a VAR model provides approximately realistic forecast values of energy consumption, GDP, and $\mathrm{CO}_{2}$ emissions of Shanxi for corresponding policy establishment to promote resource-based economic restructuring and reform and achieve sustainable development. Finally, conclusions and policy recommendations to boost coordinated development in a $3 \mathrm{E}$ system of Shanxi are presented based on results received. It is hoped that this paper can be drawn on for other regions analogous to Shanxi in energy, economy, and the environment.

\section{Method}

\section{Vector Autoregression Model}

The VAR model proposed by Sims [26] in 1980 is established based on statistical characteristics of data by making comprehensive use of information of multiple variables, and it is one of the easiest models to analyze and predict multiple related economic indicators. What's more, the VAR model can better cover abundant information and simulate the system than models using only a single time series, so it can provide more realistic predicted values when applied in forecasting, and it is also very accurate when making the near future prediction.

The multivariable VAR (P) model can be written as:

$y_{t}=\Gamma_{0}+\Phi_{1} y_{t-1}+\ldots+\Phi_{p} y_{t-p}+\varepsilon_{t}, t=1, \ldots, T$

...where $y_{t}$ represents a $k \times 1$ vector of endogenous variables, $\Phi_{t}$ denotes $k \times k$ coefficient matrices, $\varepsilon_{t}$ is the one-step ahead prediction error with variance-covariance $\operatorname{matrix} \Sigma, \Gamma_{0}$ refers to the intercept, and $p$ is lag length. As for the VAR model, the single coefficient can only reflect a local relationship and cannot capture the full impacts of one variable on the other, which is meaningless for studying the coefficients of the VAR model. Therefore, in this case, on the basis of the VAR model established, the main purpose is to analyze the dynamic relationships between variables through impulse response analysis and variance decomposition.

\section{Impulse Response Analysis}

Impulse response analysis not only fully reflects the dynamic relationship between various variables, but it also impacts the change in an endogenous variable on others in the system. Specifically, it describes impacts on 
the current or future value when a random error term is shocked from inside or outside the system.

Eq. (1) satisfies the stability condition if roots of the determinant are outside the unit circle, so that the VAR model can be expressed as an infinite vector VMA process in this case, and Eq. (1) can be rewritten as:

$$
y_{t}=\Theta(L) \varepsilon_{t}
$$

...where $L$ is the lag operator. For two conditioning random variables, if $y_{1}$ is given a unit of impulse in the base period: $\varepsilon_{1 t}=1, t=0 . \varepsilon_{1 t}=0 . t=$ others, $\varepsilon_{2 t}=0$, $t=0,1,2, \ldots$, which is called the impulse response function of $y_{2}$ caused by $y_{1}$ and which can be described as:

$$
t=0, y_{20}=\theta_{21}^{(0)} ; t=1, y_{21}=\theta_{21}^{(1)} ; t=2, y_{22}=\theta_{21}^{(2)}, \ldots,
$$

\section{Variance Decomposition}

Variance decomposition can decompose the variance of one variable in the system into each disturbance, analyzing the innovation of the endogenous variables from the impact of each structure, so that the importance of various structural shocks can be further explored. Eq. (2) can be rewritten as follows:

$y_{i t}=\sum_{j-1}^{k}\left(\theta_{i j}^{(0)} \varepsilon_{j t}+\theta_{i j}^{(1)} \varepsilon_{j t-1}+\theta_{i j}^{(2)} \varepsilon_{j t-2}+\ldots\right), i=1,2, \ldots, k, t=1,2, \ldots, T$

The content of each bracket is the sum of influence of the disturbance $\varepsilon_{j}$ from the infinite past to the present, which can be evaluated by the variance. Assuming that $\varepsilon_{j}$ is no serial correlation, variances of $y_{j}$ can be decomposed into $\mathrm{k}$ types of unrelated effects. Therefore, the relative variance contribution rate is defined for determining how much the variance of disturbance contributes to the variance of $y_{i}$.

If the VAR model meets the stability condition, the approximate relative variance contribution rate is defined as:

$$
R V C_{j \rightarrow i}(s)=\sum_{q=0}^{s-1}\left(\theta_{i j}^{q}\right)^{2} \sigma_{j j} / \sum_{j=1}^{k}\left\{\sum_{q=0}^{s-1}\left(\theta_{i j}^{(q)}\right)^{2} \sigma_{j j}\right\}
$$

...where $\sigma_{j j}$ is standard deviation of $\varepsilon_{j}$. The larger the $\sigma_{j j}$, the greater the impact of the $j_{t h}$ variable on the $i_{t h}$ variable.

\section{Data}

\section{Data Illustration}

In this paper, terminal energy consumption (unit: ten thousand tons standard coal), GDP (unit: 100 million yuan), and $\mathrm{CO}_{2}$ emissions (unit: ten thousand tons) in Shanxi are respectively deemed as indicators of energy, economy, and the environment.

There are two forms of energy consumption: one-time direct consumption, also known as terminal consumption; and the conversion processing consumption, also known as intermediate consumption. Relative to intermediate consumption, terminal energy consumption is directly invested in various devices and used for production and non-production activities $[27,28]$. In this paper, terminal energy consumption is employed to represent energy consumption in Shanxi. This indicator can largely reflect energy need and the development level of the energy industry in the region.

The economic growth of Shanxi is represented by regional gross output value in this paper.

Substantial $\mathrm{CO}_{2}$ emissions can bring extremely adverse effects on the natural environment. Coal combustion is the main source of $\mathrm{CO}_{2}$ emissions, which accounts for $79-85 \%$ of the nationwide total emissions [29]. As a dominating part in China's coal industry, coal production of Shanxi comes to more than one quarter of the total in China [30]. Therefore, energy-related $\mathrm{CO}_{2}$ emissions are selected as a representative indicator of environmental pollution in Shanxi. As there have been no specific observations in the existing statistical yearbook, with some statistics not being gathered, the estimation method was employed to calculate $\mathrm{CO}_{2}$ emissions.

\section{$\mathrm{CO}_{2}$ Emissions Measurement}

At present, there are mainly two accounting standards for $\mathrm{CO}_{2}$ emissions: one is calculated from the perspective of terminal consumption and the other from the angle of life cycle assessment (LCA).

This paper is designed to estimate energyrelated $\mathrm{CO}_{2}$ emissions using terminal fossil energy consumption based on the formula released by the 2006 Intergovernmental Panel on Climate Change (IPCC) guidelines [31]. The specific equation is shown as follows:

$$
C(t)=E(t) \sum_{i=1}^{n} s_{i}(t) c_{i}
$$

...where $C(t)$ represents total energy-related $\mathrm{CO}_{2}$ emissions at year t, $E(t)$ denotes energy consumption at year $\mathrm{t}, s_{i}(t)$ is the consumption ration of each kind of energy, $c_{i}$ refers to emission coefficient of the $i_{t h}$ kind of primary energy, and i represents energy species of $\mathrm{CO}_{2}$ sources, $\mathrm{i}=1,2, \ldots, \mathrm{n}$. Various kinds of emission factors are derived from the IPCC guidelines.

More specifically, when referring to the energy classification of the Shanxi Statistical Yearbook and considering that $\mathrm{CO}_{2}$ emission coefficients of raw coal, cleaned coal, and other kinds of coal are the same, emissions from these are incorporated and collectively 
Table 1. $\mathrm{CO}_{2}$ emission coefficients of sources of energy $\left(\mathrm{tCO}_{2} / \mathrm{tce}\right)$.

\begin{tabular}{|c|c|c|c|}
\hline $\begin{array}{c}\text { Sources } \\
\text { of energy }\end{array}$ & $\begin{array}{c}\mathrm{CO}_{2} \text { emission } \\
\text { coefficients }\end{array}$ & $\begin{array}{c}\text { Sources } \\
\text { of energy }\end{array}$ & $\begin{array}{c}\mathrm{CO}_{2} \text { emission } \\
\text { coefficients }\end{array}$ \\
\hline Raw coal & 0.7559 & Kerosene & 0.5714 \\
\hline $\begin{array}{c}\text { Cleaned } \\
\text { coal }\end{array}$ & 0.7559 & Diesel oil & 0.5921 \\
\hline Coke & 0.8550 & Fuel oil & 0.6185 \\
\hline Crude oil & 0.5857 & Natural gas & 0.4483 \\
\hline Petrol & 0.5538 & ---- & \\
\hline
\end{tabular}

called $\mathrm{CO}_{2}$ emissions from the coal. According to IPCC guidelines [32], $\mathrm{CO}_{2}$ emission coefficients of coal, coke, and natural gas are 0.7559, 0.8550, and 0.4483 , respectively. As there is no emission coefficient for petroleum but crude oil and its other products, this paper refers to the research results from Song [33] and makes the emission coefficient value of petroleum 0.5825 . $\mathrm{CO}_{2}$ sources and respective coefficients are presented in Table 1.

\section{Data Collection}

All data in this paper covering the period of 1999-2015 are derived from the Shanxi Statistical Yearbook [34]. Based on data collected, Eviews 7.2 software was utilized to make empirical studies on the development law and internal relations in the $3 \mathrm{E}$ system of Shanxi Province.

\section{Results}

The Changing Tendencies of Economic Growth, Energy Consumption, and $\mathrm{CO}_{2}$ Emissions in Shanxi

The changing tendencies of economic growth, energy consumption, and $\mathrm{CO}_{2}$ emissions are shown in the following three figures, where EC represents terminal energy consumption, GDP refers to the regional gross

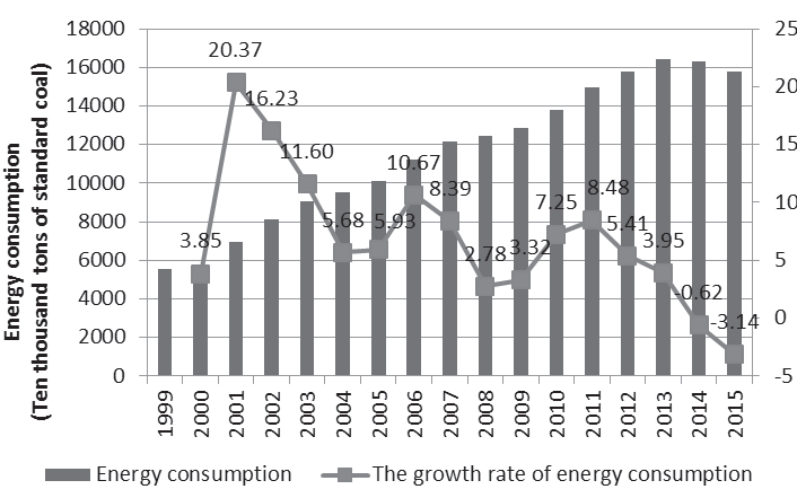

Fig. 2. Change in energy consumption from 1999 to 2015.

output value of Shanxi Province, and DCE denotes the amount of energy-related $\mathrm{CO}_{2}$ emissions.

As can be seen in Fig. 1, we have seen a continuously growing trend of economic development in Shanxi Province generally. More concretely, the real GDP growth from 1999 to 2007 is comparatively rapid with an increasing trend year by year; nevertheless, a decline from 2008 caused by the global financial crisis, Shanxi's economic growth dropped sharply showing a distinct downward pressure on GDP growth only with an annual growth rate of 5.4\% from 2008 to 2009. Since then, the economy continued to maintain rapid growth. The downturn of coal markets and the rapid drop of energy prices since 2013 had caused a severely negative shock to the economy of Shanxi. The GDP growth rate was $4.9 \%$ from 2013 to 2014 and $3.1 \%$ from 2014 to 2015 , lower than that of the national average rate at that time.

What is shown in Fig. 2 indicates that energy consumption of Shanxi has overall increased with fluctuations, with the consumption of standard coal increasing from 5573.19 ten thousand tons in 1999 to 15803.31 ten thousand tons in 2012, rising by a comparatively high speed on the whole. Since 2013, the sluggish macro economy has led to a downturn in coal demand growth [35]. As a main coal-dominating province, Shanxi has been severely affected so that energy consumption has started to decline slowly.

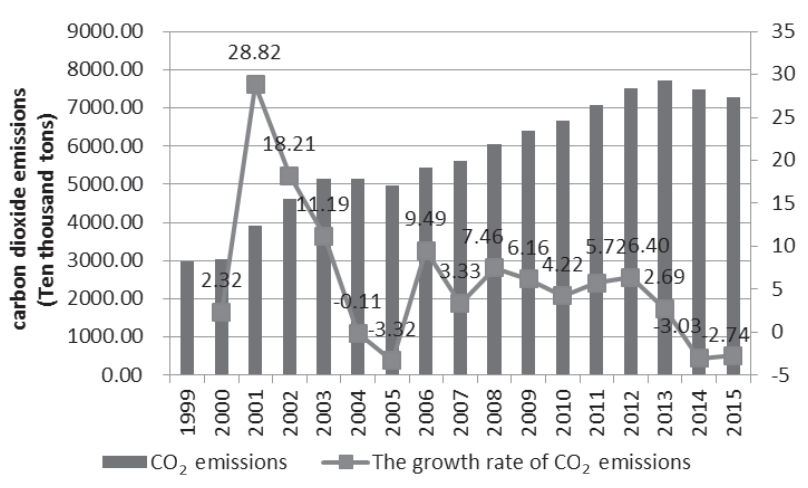

Fig. 3. Change in carbon dioxide emissions from 1999 to 2015.
Fig. 1. Change in GDP from 1999 to 2015.

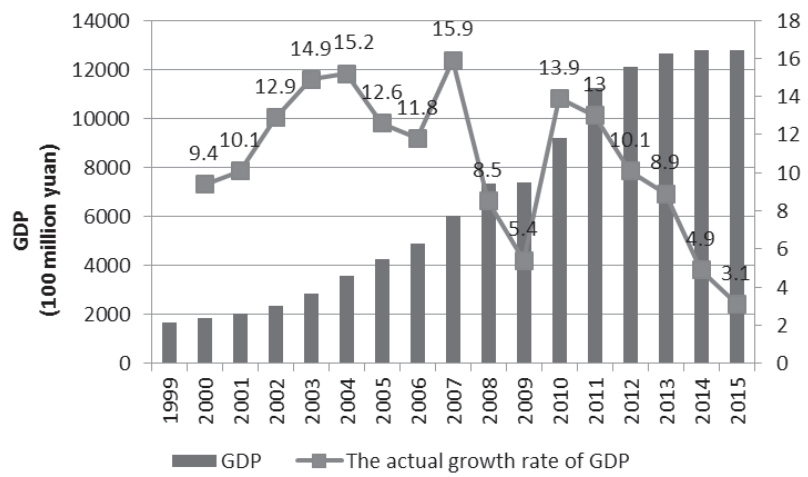

\section{.

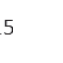
(n)

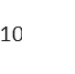




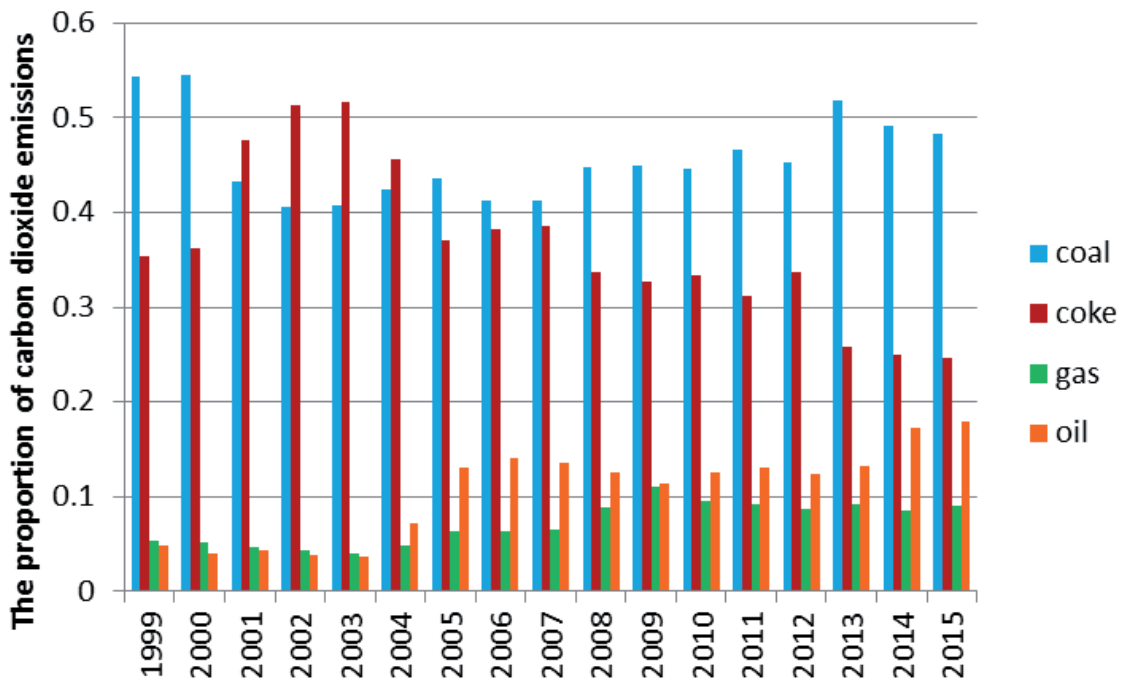

Fig. 4. Changes in proportion of each source to carbon dioxide emissions.

Fig. 3 demonstrates a sharp increasing trend of $\mathrm{CO}_{2}$ emissions overall. More specifically, $\mathrm{CO}_{2}$ emissions caused by energy depletion in Shanxi increased to 7274 ten thousand tons in 2015 from 2967 ten thousand tons in 1999, rising by 2.4 times, with especially the annual growth rate being $7.3 \%$ from 1999 to 2012. And the quantity of those in 2013 was 7713 ten thousand tons, reaching its peak value. It was in 2013 that $\mathrm{CO}_{2}$ emissions began to diminish at a slow pace, because the local government has spared no effort to transform the energy industry in the region under pressure from emission reduction and strict environmental policies.

As shown in Fig. 4, from a sectional perspective, the coal and coke remained to be leading parts in $\mathrm{CO}_{2}$ sources in the past, accounting for approximately $80 \%$ of total energy-related $\mathrm{CO}_{2}$ emissions from 1999 to 2005 . While this percentage has declined with small fluctuations from 2006 to 2015, it still remained above $70 \%$. As for oil, $\mathrm{CO}_{2}$ emissions from that has always accounted for a comparatively tiny proportion of the whole - and only $9.1 \%$ of total $\mathrm{CO}_{2}$ emissions in 2015 . Last but not least, although the proportion of emissions from natural gas showed a general trend of growth, the increasing rate was very slow, and only $17.9 \%$ by the end of 2015. This shows that the energy consumption of coal and coke has a serious impact on the environment. Relevant departments should vigorously develop clean energy and improve energy structure to reduce $\mathrm{CO}_{2}$ emissions.

The traditional VAR model requires that every variable should be stationary. For non-stationary variables, differential processing needs to be performed to obtain a stationary time series to establish a VAR model, which will nevertheless lose the corresponding level information. However, with the development

Table 2. Statistical results of ADF test.

\begin{tabular}{|c|c|c|c|c|c|c|}
\hline Variable & $\begin{array}{c}\text { Test type } \\
(\mathrm{c}, \mathrm{t}, \mathrm{p})\end{array}$ & $\begin{array}{c}\mathrm{ADF} \\
\text { statistics }\end{array}$ & $\begin{array}{c}10 \% \text { Critical } \\
\text { values }\end{array}$ & $\begin{array}{c}5 \% \text { Critical } \\
\text { values }\end{array}$ & $\begin{array}{c}\mathrm{P} \\
\text { value }\end{array}$ & Result \\
\hline $\mathrm{EC}$ & $(\mathrm{c}, 1,2)$ & 0.1686 & -3.3423 & -3.7912 & 0.9942 & nonstationary \\
\hline $\mathrm{D}(\mathrm{EC})$ & $(\mathrm{c}, 1,1)$ & -0.3978 & -3.3423 & -3.7912 & 0.3644 & nonstationary \\
\hline $\mathrm{D}(\mathrm{EC}, 2)$ & $(\mathrm{c}, 0,1)$ & $-3.1928^{* *}$ & -2.7011 & -3.1199 & 0.0442 & stationary \\
\hline $\mathrm{GDP}$ & $(\mathrm{c}, 1,1)$ & -2.3258 & -3.3350 & -3.7597 & 0.3974 & nonstationary \\
\hline $\mathrm{D}(\mathrm{GDP})$ & $(\mathrm{c}, 1,0)$ & -2.1347 & -3.3350 & -3.7597 & 0.4876 & nonstationary \\
\hline $\mathrm{D}(\mathrm{GDP}, 2)$ & $(\mathrm{c}, 0,0)$ & $-4.3985 * * *$ & -2.6904 & -3.0989 & 0.0050 & stationary \\
\hline $\mathrm{CO}{ }_{2}$ & $(\mathrm{c}, 1,1)$ & -2.0247 & -3.3350 & -3.7597 & 0.2743 & nonstationary \\
\hline $\mathrm{D}\left(\mathrm{CO}_{2}\right)$ & $(\mathrm{c}, 1,0)$ & -3.0472 & -3.3350 & -3.7597 & 0.1528 & nonstationary \\
\hline $\mathrm{D}\left(\mathrm{CO}_{2}, 2\right)$ & $(\mathrm{c}, 0,0)$ & $-5.0601 * * *$ & -2.6904 & -3.0989 & 0.0016 & stationary \\
\hline
\end{tabular}

Note: $(c, t, P)$ is the test type, where $\mathrm{c}$ is the intercept, $\mathrm{t}$ is the trend, $\mathrm{p}$ is the lag length, Zero value means there is no such item . lag order selected by the SIC criterion. ***, **, * respectively denote the rejection of the null hypothesis at $1 \%, 5 \%, 10 \%$ significance level. 
Table 3. Optimum lags selection.

\begin{tabular}{|c|c|c|c|c|c|c|}
\hline Lag & LogL & LR & FPE & AIC & SC & HQ \\
\hline 0 & -359.4485 & NA & $1.95 \mathrm{e}+17$ & 48.3265 & 48.4681 & 48.3250 \\
\hline 1 & -314.8885 & $65.3546^{*}$ & $1.77 \mathrm{e}+15^{*}$ & $43.5851^{*}$ & $44.1516^{*}$ & $43.5791^{*}$ \\
\hline 2 & -307.7041 & 7.6633 & $2.74 \mathrm{e}+15$ & 43.8272 & 44.8185 & 43.8167 \\
\hline
\end{tabular}

Note:* indicates lag order selected by the criterion.

Table 4. Statistical results of the trace tests.

\begin{tabular}{|c|c|c|c|c|}
\hline \multirow{2}{*}{$\begin{array}{c}\text { Null } \\
\text { hypothesis }\end{array}$} & \multirow{2}{*}{ Eigenvalue } & Trace & $5 \%$ & $\mathrm{P}$ \\
\cline { 3 - 5 } & Statistic & $\begin{array}{c}\text { Critical } \\
\text { Values }\end{array}$ & Value \\
\hline None & 0.8349 & 37.1211 & 35.1928 & 0.0306 \\
\hline At most 1 & 0.3833 & 10.1040 & 20.2618 & 0.6296 \\
\hline At most 2 & 0.1733 & 2.8544 & 9.1646 & 0.6083 \\
\hline
\end{tabular}

of cointegration theory, VAR models can be directly established as long as there are cointegration relationships between variables [36].

It should be the first to conduct the stationarity test to determine the stationarity of variables and its order of integration, methods of which commonly include the augmented Dickey-Fuller (ADF) test and the nonparametric Phillips-Perron (PP) test [37], and the ADF test is employed in this paper.

As can be seen from Table 2, for the original sequence and the first difference of EC, GDP, and $\mathrm{CO}_{2}$, the corresponding ADF statistics are greater than the critical value at the $10 \%$ significance level, indicating that the original sequence and the first difference of these three variables are all non-stationary. Tests performed on the second differences strongly demonstrate that the second difference of each time series is stationary at the $5 \%$ significance level, that is, these series are integrated of order second.

As for the cointegration test, variables are required to be integrated. Results of the stationarity test demonstrate that all variables are integrated of order second, so it is reasonable to perform the cointegration test of these variables. The Engle-Granger (E-G) test, based on the regression residual applied to the bivariate, and

Table 5. Statistical results of the maximum eigenvalue test.

\begin{tabular}{|c|c|c|c|c|}
\hline & & Max-Eigen & $5 \%$ & $\mathrm{P}$ \\
\hline $\begin{array}{c}\text { Null } \\
\text { hypothesis }\end{array}$ & Eigenvalue & Statistic & $\begin{array}{c}\text { Critical } \\
\text { Values }\end{array}$ & Value \\
\hline None & 0.8349 & 27.0171 & 22.2996 & 0.0102 \\
\hline At most 1 & 0.3833 & 7.2496 & 15.8921 & 0.6390 \\
\hline At most 2 & 0.1733 & 2.8544 & 9.1646 & 0.6083 \\
\hline
\end{tabular}

the Johansen-Juselius (JJ) test, based on the regression coefficient for the multivariate, are two mainly used cointegration test approaches. In our model, the JJ test method is utilized.

Before the cointegration test, the optimal lag length should be determined, whose specific operating is expressed as follows: starting from a larger lag order, the optimal lag length can be determined by comprehensive judgment through the LR, FPE, AIC, SC, and HQ values. From Table 3, the test results illustrates that the optimum lag length is one.

According to characteristics of the data, we choose the linear tendency of the sequence, but the equation only has the test form of intercept. The statistical results of the trace test presented in Table 4 demonstrate that null hypothesis of no cointegration relationships is rejected at the 5\% significance level. Therefore, there exists a cointegration relationship among variables. It can also illustrate the same conclusion from the maximum eigenvalue test results in Table 5 .

Hence, the VAR model can be used to analyze the dynamic relationships among variables in this system. The VAR model can be represented by the following equation:

$\left\{\begin{array}{l}E C=0.9515 * E C(-1)-0.0869 * G D P(-1)+0.2092 * C_{2}(-1)+570.8584 \\ G D P=0.4170 * E C(-1)+0.6817 * G D P(-1)-0.0879 * C O_{2}(-1)-1505.0425 \\ \mathrm{CO}_{2}=0.0972 * E C(-1)-0.0027 * G D P(-1)+0.6735 * C O_{2}(-1)+1016.4031\end{array}\right.$

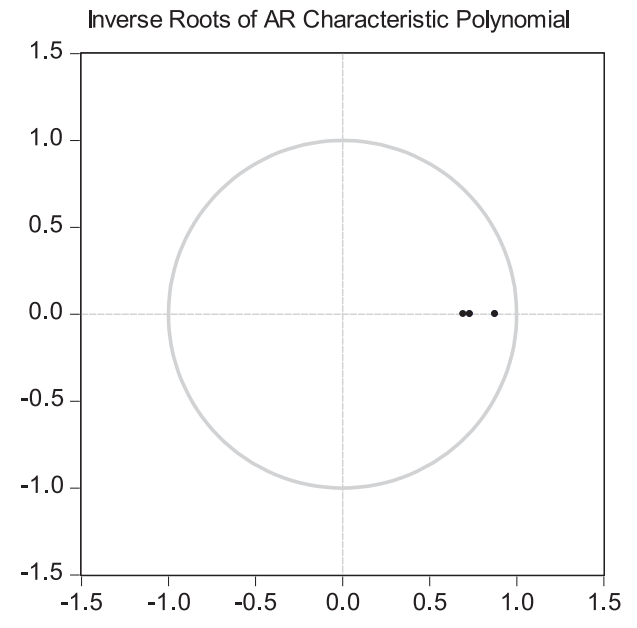

Fig. 5. Findings from the stability test of the VAR model. 


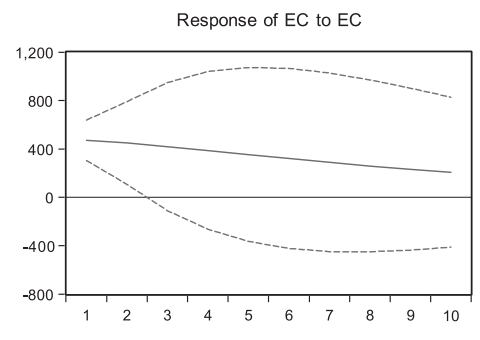

Response to Nonfactorized One S.D. Innovations?2 S.E.
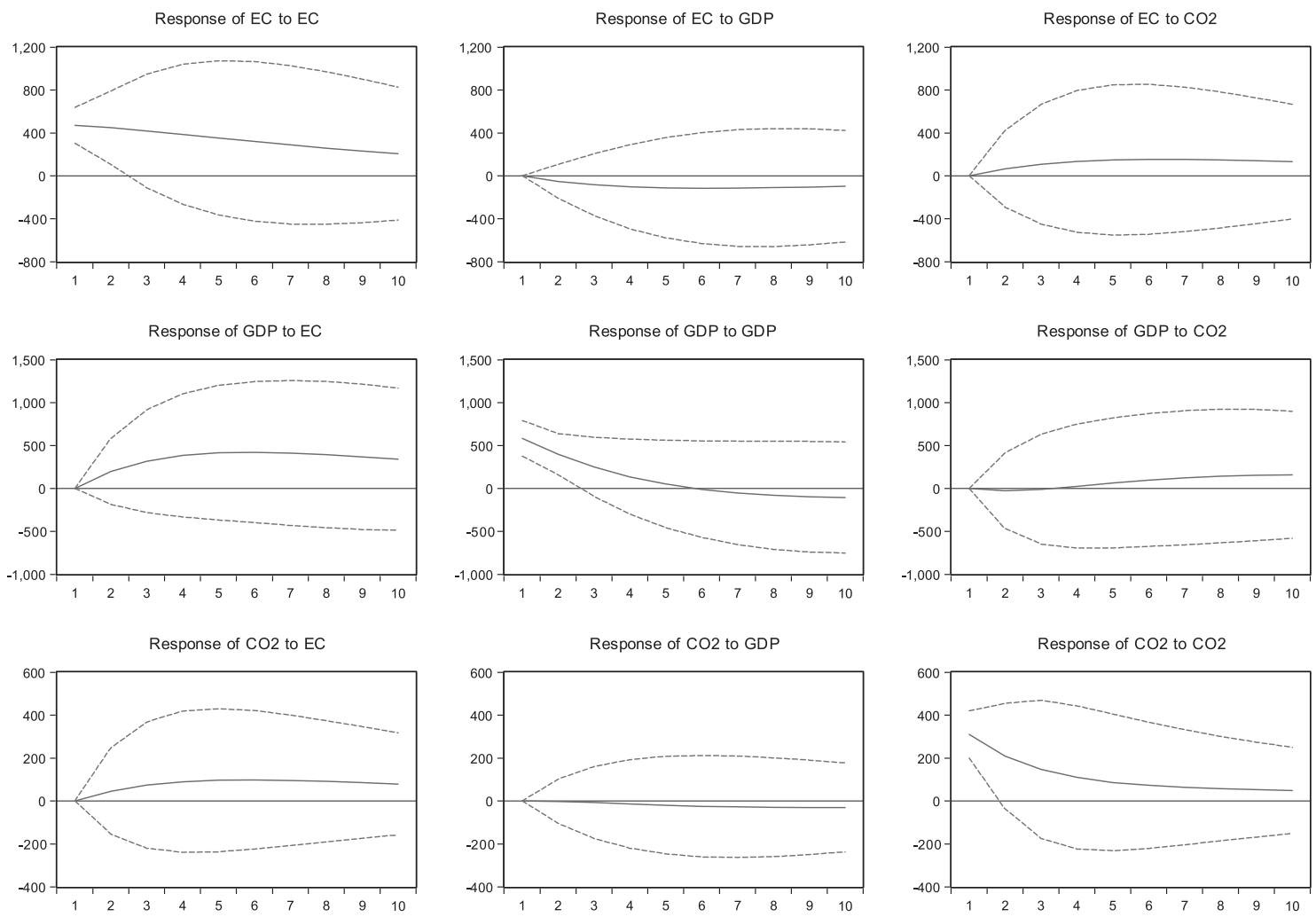

Fig. 6. Findings from the impulse response function.

Impulse Response Function Analysis

The stability of VAR needs to be tested before the impulse response function analysis, which is not suitable for the unstable VAR model [38]. The model will be stable if estimated absolute values of all inverse characteristic roots of the characteristic equation for VAR are less than one, i.e., inverse roots of AR characteristic polynomial are within the unit circle.
As can be seen from Fig. 5, absolute values of all unit roots are within the unit circle. Therefore, the VAR model satisfies the stability conditions so that impulse response function analysis can be performed.

From Fig. 6, energy consumption responds positively to one standard deviation positive change in itself, and this response gradually weakened; a positive shock in economic growth has a negative impact on energy consumption, stabilizing after the third period; a one

Table 6. Findings from variance decomposition.

\begin{tabular}{|c|c|c|c|c|c|c|c|c|c|}
\hline \multirow{2}{*}{$\begin{array}{c}\text { Quarter } \\
\text { horizon }\end{array}$} & \multicolumn{2}{|c|}{ Variance decomposition of EC } & \multicolumn{3}{|c|}{ Variance decomposition of GDP } & \multicolumn{4}{|c|}{ Variance decomposition of $\mathrm{CO}_{2}$} \\
\cline { 2 - 12 } & $\mathrm{EC}$ & $\mathrm{GDP}$ & $\mathrm{CO}_{2}$ & $\mathrm{EC}$ & $\mathrm{GDP}$ & $\mathrm{CO}_{2}$ & $\mathrm{EC}$ & $\mathrm{GDP}_{2}$ & $\mathrm{CO}_{2}$ \\
\hline 1 & 100.00 & 0.00 & 0.00 & 37.28 & 62.72 & 0.00 & 64.54 & 3.65 & 31.82 \\
\hline 2 & 99.08 & 0.62 & 0.30 & 48.77 & 51.19 & 0.04 & 68.35 & 3.32 & 28.34 \\
\hline 3 & 97.70 & 1.54 & 0.76 & 59.07 & 40.90 & 0.03 & 71.18 & 3.17 & 25.65 \\
\hline 4 & 96.27 & 2.49 & 1.24 & 67.20 & 32.76 & 0.04 & 73.25 & 3.14 & 23.61 \\
\hline 5 & 94.96 & 3.36 & 1.69 & 73.03 & 26.84 & 0.13 & 74.74 & 3.21 & 22.05 \\
\hline 6 & 93.81 & 4.11 & 2.08 & 76.93 & 22.77 & 0.30 & 75.81 & 3.33 & 20.86 \\
\hline 7 & 92.84 & 4.74 & 2.42 & 79.42 & 20.06 & 0.52 & 76.56 & 3.50 & 19.94 \\
\hline 8 & 92.04 & 5.26 & 2.70 & 80.93 & 18.29 & 0.78 & 77.08 & 3.68 & 19.24 \\
\hline 9 & 91.38 & 5.69 & 2.94 & 81.81 & 17.15 & 1.04 & 77.44 & 3.87 & 18.69 \\
\hline 10 & 90.84 & 6.03 & 3.13 & 82.29 & 16.42 & 1.29 & 77.68 & 4.06 & 18.27 \\
\hline
\end{tabular}


Table 7. Percentage predicted error.

\begin{tabular}{|c|c|c|c|}
\hline Period & $\mathrm{EC}$ & GDP & $\mathrm{CO}_{2}$ \\
\hline 2000 & 7.832 & -3.728 & 8.526 \\
\hline 2001 & 3.345 & -1.212 & 2.747 \\
\hline 2002 & 0.001 & 2.487 & -3.588 \\
\hline 2003 & -0.604 & 4.488 & -4.675 \\
\hline 2004 & 2.941 & 4.594 & -0.755 \\
\hline 2005 & 4.025 & 6.190 & 4.978 \\
\hline 2006 & 1.889 & 8.668 & 3.174 \\
\hline 2007 & -0.188 & 5.052 & 4.294 \\
\hline 2008 & 2.210 & 1.633 & 2.177 \\
\hline 2009 & 3.385 & 6.880 & -0.254 \\
\hline 2010 & 0.315 & 0.562 & -1.259 \\
\hline 2011 & -3.566 & -6.324 & -2.120 \\
\hline 2012 & -4.053 & -7.836 & -5.089 \\
\hline 2013 & -5.494 & -6.754 & -5.600 \\
\hline 2014 & -3.472 & -3.145 & -2.298 \\
\hline 2015 & -0.223 & 1.686 & 1.228 \\
\hline
\end{tabular}

standard deviation positive change to $\mathrm{CO}_{2}$ emissions positively affects energy consumption, and this effect tends to be flat after the third period; a positive change in energy consumption exerts a stronger effect on economic growth, and this effect is relatively long-lived; a shock to economic growth positively effects itself while this response is relatively short-lived, and furthermore, gradually decreases and turns slightly negative in the fifth period; a positive change in $\mathrm{CO}_{2}$ emissions has a negative impact on economic growth, but this response turns positive in the third period, stable after the eighth period; a positive shock in energy consumption positively affects $\mathrm{CO}_{2}$ emissions, climaxing in the fourth period; a positive change in economic growth exerts a slightly negative effect on $\mathrm{CO}_{2}$ emissions; $\mathrm{CO}_{2}$ emissions respond positively to a one standard deviation positive shock in itself, but this response gradually weakened and stabilized after the fourth period.

\section{Variance Decomposition}

Table 6 indicates that the shock to energy consumption account is $100 \%$ and $90.84 \%$, fluctuation in energy consumption in the first quarter and tenth quarter horizons, respectively. Fluctuation in energy consumption from 0 to $6.03 \%$ can be explained by the innovation to GDP, showing a rising trend from the first period to the tenth period, and can also be attributed to innovations in $\mathrm{CO}_{2}$ emissions ranging from 0 to $3.13 \%$, the innovation of which has been increasing over the ten quarters. The shock to energy consumption accounts
Table 8. Predicted values from 2016 to 2023 .

\begin{tabular}{|c|c|c|c|}
\hline Year & EC & GDP & $\mathrm{CO}_{2}$ \\
\hline 2016 & 16043.80 & 12902.53 & 7475.88 \\
\hline 2017 & 16279.22 & 13324.01 & 7575.46 \\
\hline 2018 & 16487.43 & 13700.76 & 7664.25 \\
\hline 2019 & 16671.39 & 14036.62 & 7743.24 \\
\hline 2020 & 16833.76 & 14335.36 & 7813.39 \\
\hline 2021 & 16976.98 & 14600.56 & 7875.60 \\
\hline 2022 & 17103.23 & 14835.61 & 7930.68 \\
\hline 2023 & 17214.45 & 15043.66 & 7979.40 \\
\hline
\end{tabular}

for $37.28 \%$ and $82.29 \%$ fluctuation in GDP in the first quarter and tenth quarter horizons, respectively. The innovation to GDP accounts for $62.72 \%$ and $16.42 \%$ fluctuation in itself in the first horizon and tenth quarter horizon, respectively, and it has been a downward trend from 1 to 10 quarters. GDP can be explained for innovations in $\mathrm{CO}_{2}$ emissions ranging from 0 to $1.29 \%$. $\mathrm{CO}_{2}$ emissions can be attributed to innovations in energy consumption from $64.53 \%$ to $77.68 \%$, in GDP from $3.65 \%$ to $4.06 \%$, and in itself from $18.27 \%$ to $31.82 \%$.

\section{Forecasting the VAR Model}

This study forecasts the data from 1999 to 2023 by using the VAR model established from energy consumption, GDP, and $\mathrm{CO}_{2}$ emissions in Shanxi and calculates the percentage predicted error from 1999 to 2015. The results are shown in Table 7.

By comparing predicted values and actual ones, it can be seen that the percentage of predictive error between predicted and actual values of energy consumption is very small except for some individual years, with the percentage only being $0.001 \%$ in $2002,-0.188 \%$ in 2007 , and $-0.223 \%$ in 2015 . The prediction error percentage of GDP and $\mathrm{CO}_{2}$ emissions are also relatively small, only $0.562 \%$ in 2010 and $-0.254 \%$ in 2009 , respectively. In summary, it is reasonable to conclude that the VAR model has a good forecasting effect.

Results in Table 8 indicate that energy consumption, GDP, and $\mathrm{CO}_{2}$ emissions of Shanxi are continually increasing in the next few years. By 2023, energy consumption will increase to 17214.45 ten thousand tons of standard coal, the GDP will rise to 15043.66 hundreds million Yuan, and $\mathrm{CO}_{2}$ emissions will grow to 7979.40 ten thousand tons.

\section{Discussion}

1. Energy consumption, GDP, and $\mathrm{CO}_{2}$ emissions are all integrated of order second and subject to longterm equilibrium relationship. The VAR model can be established accordingly to explore the dynamic 
connection between them and predict their future tendency.

2. Based on the impulse response analysis, a positive shock in economic growth would have a negative impact on energy consumption, which can be attributed to the gradual scarcity of resources, making Shanxi less dependent on energy in its economic development. A positive change in energy consumption exerts a stronger effect on economic growth, with this effect being relatively long-lived. The reason for this trend is that, although having relatively decreased energy depletion in economic progress recently, it is obvious and prominent that the coal-dominated energy industry still plays a primary role in promoting economic development in Shanxi, and that rapid economic growth still needs energy support in the future [39].

3. An increment change in $\mathrm{CO}_{2}$ emissions can positively affect energy consumption, and in turn a positive shock in energy consumption also has a positive effect on $\mathrm{CO}_{2}$ emissions. What can apparently be concluded is that huge energy demand and extensive mode of growth will produce tremendous pressure on Shanxi to save energy and reduce emissions, bringing a difficult problem for the local government in the short term to achieve rapid reduction of $\mathrm{CO}_{2}$ emissions. However, it is possible to reduce the growth rate of $\mathrm{CO}_{2}$ emissions through rational industrial restructure and strict energy optimization policies [40, 41].

4. A positive change in $\mathrm{CO}_{2}$ emissions has a negative impact on economic growth in the short term, but $\mathrm{CO}_{2}$ emissions respond positively to a positive change in economic growth in the long run. This demonstrates that Shanxi has taken the coal, thermal power, steel-making, and other energy-consuming industries as its leading industries and developed the single economy at the expense of resources and environment for a long time. A positive change in economic growth exerts a slightly negative effect on $\mathrm{CO}_{2}$ emissions. What can explain this tendency may be that Shanxi, a traditional energy industry province, has further boosted economies of scale as local economic development, leading to an increase in total factor productivity. This has effectively eased regional $\mathrm{CO}_{2}$ emissions from energy consumption.

5. From the variance decomposition results, energy consumption can be attributed to innovations in itself from $90.84 \%$ to $100 \%$ ranges, indicating that energy consumption is mainly affected by itself, with extraordinarily small innovations from GDP and $\mathrm{CO}_{2}$ emissions. The innovation to energy consumption for fluctuation in GDP continues to be increasing, which accounts for an $82.29 \%$ change of GDP in the long run, meaning that medium and long-term energy consumption has an important contribution to the economic development of Shanxi. This tendency mainly arises from the fact that Shanxi is rich in coal and other mineral resources and the local resource attribute determines that its economic development inevitably relies on large-scale energy exploitation and utilization. The innovation to $\mathrm{CO}_{2}$ emissions account is from $64.53 \%$ to $77.68 \%$ fluctuation in energy consumption, which shows that $\mathrm{CO}_{2}$ emissions in Shanxi are greatly influenced by energy consumption, related to the unreasonable energy structure that is mainly dominated by high-polluting coal in this area [42]. Consequently, environmental protection has become a vital problem to be solved for the energy industry to achieve sustainable development in Shanxi.

6. Small prediction errors make the VAR model able to perfectly predict the long-term trend of variables in the system. According to the predictions of the VAR model, energy consumption, GDP, and $\mathrm{CO}_{2}$ emissions in Shanxi show a trend of increasing year by year. Meanwhile, the crisis of energy exhaustion, the drawback of extensive economic growth, and environmental pollution will have gradually emerged in the future. As a result, the government and relevant departments should effectively adopt reasonable policies to increase energy efficiency and improve the ecological environment to realize sustainable development while pursuing rapid economic growth.

\section{Conclusions and Policy Implications}

\section{Conclusions}

This paper explores the dynamic relationship between 3E systems in Shanxi through the VAR model. It can been obtained from the impulse response analysis that a positive shock in economic growth has a negative impact on energy consumption, a positive change in energy consumption exerts a stronger effect on economic growth, and a positive shock in energy consumption also has a positive effect on $\mathrm{CO}_{2}$ emissions, with all of those responses being relatively long-lived. The variance decomposition results indicate that the innovation to energy consumption accounts for $82.29 \%$ fluctuation in GDP in the long run, and $\mathrm{CO}_{2}$ emissions can be attributed to innovations in energy consumption of about $70 \%$. The forecast results manifest that energy consumption, GDP, and $\mathrm{CO}_{2}$ emissions in Shanxi Province all have an increasing trend year by year.

\section{Policy Implications}

These conclusions are illuminating for attracting attention from local policy-makers. Specific implications are summarized as follows in respect to the economy, energy, and environment in order to ameliorate the conventional coal-dominating situation, earnestly implement the new Five Development Concept, and accomplish in-depth reform of a resourcebased economy and green sustainable development in Shanxi. 


\section{Policy Implications}

Recently, the Shanxi government has spared no effort to solve the "resource curse" problem and handle increasingly severe environmental issues - especially huge $\mathrm{CO}_{2}$ emissions from energy consumption, achieving mitigation of ecological protection situation to some extent. To better solve the imbalanced, uncoordinated, and unsustainable development issues mentioned in the Thirteenth Five-year Plan for Economic and Social Development in Shanxi Province [9] for accomplishing the aim to build ecological civilization, relevant measures can be taken from the following three aspects:

1. Optimize industrial structure and transform economic development mode.

The coal-dominated energy industry has a prominent impetus to the economic development of Shanxi Province. Shanxi should make rational use of coal resources, strengthen the processing and conversion capacity of coal, lengthen the coal industrial chain, and vigorously promote the novel coal chemical industry. It is rewarding to change the local economic mode mainly based on pure coal transportation, exploit coal to generate electricity, and raise the level of electrical delivery. Meanwhile, acceleration in the advance of coking industry and improving chemical and cement industries will achieve more broad utilization of fossil energy.

Besides, given less energy consumption in the primary and tertiary industries, Shanxi should give full play to its advantages in agricultural resources. It is beneficial and necessary to promote the structural reform of the agricultural supply side, develop organic dry farming, establish high-quality cereals producing areas, and actively promote green agricultural and sideline products to develop new modern agriculture.

Due to a long history and rich red tourism resources, there will be also an urgent need for the Shanxi government to vigorously develop the tourism industry and promote the integration of culture and tourism. The Three Jin Culture and Shanxi Merchants Spirit deserve the positive enhancement building a pillar industry of cultural tourism. Furthermore, tourism reform and innovation pilot area should be erected, and finally accelerate the transformation of tourism resources to economic advantages.

2. Reform the energy structure and propel diversified energy consumption.

Energy consumption of Shanxi is mainly dominated by the coal of primary energy source. Owing to its high pollution and nonrenewable properties, the overuse of coal should be slashed dramatically, and green renewable energy deserves to be boosted actively. Thus relevant departments ought to expedite the implementation of "coal-to-gas" projects for civil and industrial use and other key alternative areas.

As a province with an abundant coalbed methane (CBM) resource, Shanxi has a well-distributed coalbed methane field with good conditions, so that it would be helpful to increase the development and utilization of coalbed methane resources. Meanwhile, with rich resources of solar and wind energy, it is necessary and beneficial to steadily and smoothly push forward the construction of photovoltaic bases and northern Shanxi wind power bases, which will be of great help for the amelioration of a conventional coal-dominating situation. The progress of other new energy sources should be strengthened persistently, with the development relationship between traditional and new energy sources being coordinated.

3. Increase environmental investment and enhance lowcarbon technological innovation.

Environmental technology should be given top priority in terms of $R \& D$ investment, playing its critical role in technological progress in the energy conservation and development of a low-carbon economy. Financial subsidies for "coal-to-electricity" of rural power grid reform and optimization project should be augmented to actualize a virtuous circle of an energy production system.

Priorities for technological aspects should be vigorously driving the comprehensive utilization of coal to stimulate key areas such as coking and coal chemical industry to implement technology transformation for cleaner production. In addition, it is vital to continuously enhance the capability of independent innovation of the coal industry, extending the value chain of coal resources and increasing added value of the coal industry. Furthermore, the implementation of ultra-low emissions and energy-saving transformation for coalfired units and clean coal power generation technology will improve the overall quality of the coal industry in Shanxi Province.

\section{Acknowledgements}

This work was supported by the National Natural Science Foundation of China (No. 71471061) and the National Social Science Foundation of China (No. 15BGL145).

\section{Conflict of Interest}

The authors declare no conflict of interest.

\section{References}

1. HU H., ZHANG X., LIN L. The interactions between China's economic growth, energy production and consumption and the related air emissions during 2000-2011. Ecological Indicators, 46, 38, 2014.

2. FU Z., XIE Y., LI W., LU W., GUO H. An inexact multiobjective programming model for an economy-energyenvironment system under uncertainty: A case study of Urumqi, China. Energy, 126, 165, 2017. 
3. SUN W., MENG M., HE Y., CHANG, H. CO Emissions from China's Power Industry: Scenarios and Policies for 13th Five-Year Plan. Energies, 9 (10), 825, 2016.

4. TAN X., WANG X. The market performance of carbon trading in China: A theoretical framework of structureconduct-performance. Journal of Cleaner Production, 159, 410, 2017.

5. HU Z., YUAN J., HU Z. Study on China's low carbon development in an Economy-Energy-Electricity-Environment framework. Energy Policy, 39 (5), 2596, 2011.

6. WANG Q., YUAN X., CHENG X., MU R., ZUO J. Coordinated development of energy, economy and environment subsystems - A case study. Ecological Indicators, 46, 514, 2014.

7. Energy Statistics Division of National Bureau of Statistics of China. China Energy Statistical Yearbook of 2016. China Statistics Press, Beijing, 2017.

8. PAN X. Thoughts on Establishing Ecological Rehabilitation Mechanism in Shanxi Province. Shanxi Finance and Tax, 1 (1), 16, 2016.

9. Shanxi Provincial Development and Reform Commission. Outline of the $13^{\text {th }}$ Five-Year Plan of Shanxi Province for Economic and Social Development. Retrieved January 7, 2018, from http://www.sxdrc.gov.cn/xxlm/fzgh2/ zhdt/201605/t20160503 174212.htm 2016.

10. GASPARATOS, A., \& GADDA, T. Environmental support, energy security and economic growth in Japan. Energy Policy, 37 (10), 4038, 2009.

11. ZHAO F. Empirical study on the coordinated development of China's energy-economy-environment (3E). Economist, 12, 35, 2009.

12. WANG G., LIU J. Research on evaluation of coordinating degree of regional energy-economy-environment system based on AHP-GRAM model. In 2010 International Conference on Machine Learning and Cybernetics 5, 2276, 2010.

13. LI Z. An econometric study on China's economy, energy and environment to the year 2030. Energy Policy, 31 (11), 1137, 2003.

14. YANG C., JACKSON R.B. China's growing methanol economy and its implications for energy and the environment. Energy Policy, 41, 878, 2012.

15. TANG X., MCLELLAN B.C., SNOWDEN S., ZHANG B., HOOK M. Dilemmas for China: Energy, economy and environment. Sustainability (Switzerland), 7 (5), 5508, 2015.

16. HAN S., ZHU J. Research on the dynamic relationship of the Energy- Economy-Environment (3E) system-based on an empirical analysis of China. In Energy Procedia 5, 2397, 2011

17. LIU Z. The dynamic analysis of china's energy-economyenvironment system: VAR and VEC modeling. Advances in Information Sciences and Service Sciences, 4, 210, 2012.

18. GUAN H.A., ZOU S.L., ZHOU X.D., HUANG Z.T. Research on Coordinated Evaluation of Regional EnergyEconomy-Environment System 225, 593, Applied Informatics \& Communication-international Conference. 2011.

19. ZUO Y., SHI Y., ZHANG Y. Research on the sustainable development of an economic-energy-environment (3E) system based on system dynamics (SD): A case study of the Beijing-Tianjin-Hebei Region in China. Sustainability, 9 (10), 2017.
20. ZHAO T., LI X. On the Coordinating Evaluation Model for Energy-Economy-Environment System. Journal of Beijing Institute of Technology, 10 (2), 11, 2008.

21. LIU Q., ZHOU W. An Empirical Study on the Coordinated Development of Economy, Energy and Environment in Guangdong Province. Economic Forum, 2, 19, 2014.

22. JIN L., CHANG H., ZHAO S., XU C. The Evolution of Coupling Relationship Among Energy, Economy and Environment in Shandong Province. Economic Geography, 9, 42, 2016V

23. ZHANG G. Harmonious Development of Regional Energy, Environment and Economy. Tianjin University. 2007.

24. ZHANG L. Strategic Thinking of Low-carbon Economy Development in Shanxi Province. Energy of China, 32 (2), 10, 2010.

25. HUANG R., XIAO H., BIAN J. Empirical Study on the Relationship between Energy, Environment and Economy. Journal of Yangzhou University (Social Sciences Edition), 15 (1), 83, 2011.

26. SIMS C.A. Macroeconomics and Reality. Econometrica, 48 (1), 1, 1980.

27. LANDWEHR M., JOCHEM E. From primary to final energy consumption-Analysing structural and efficiency changes on the energy supply side. Energy Policy, 25 (7-9), 693, 1997.

28. LEE C. Energy consumption and GDP in developing countries: A cointegrated panel analysis. Energy Economics, 27 (3), 415, 2005.

29. GUO Y., ZHENG J., GE Q. Study on the primary energy related carbon dioxide emissions in China. Geographical Research, 29 (6), 1027, 2010.

30. WANG B., HUANG J. Relationship between Energy Supply,Energy Consumption and Economic Growth:Emprical Study Based on Data on Shanxi Province from 1978 to 2008. Technology Economics, 29 (2), 74, 2010.

31. WEN L., CAO Y., WENG J. Factor Decomposition Analysis of China's Energy-Related $\mathrm{CO}_{2}$ Emissions Using Extended STIRPAT Model. Polish Journal of Environmental Studies, 24 (5), 2261, 2015.

32. IPCC. Task Force on National Greenhouse Gas Inventories. Revised 1996 IPCC Guidelines for National Greenhouse Gas Inventories. Retrieved February 3, 2018, from http://www.ipcc-nggip.iges.or.jp/public/2006gl/ index.html 1996.

33. SONG J. Factor Decomposition of Carbon Emissions from Energy Consumption of Shandong Province Based on LMDI. Resources Science, 34 (1), 35, 2012.

34. Bureau of Statistics of Shanxi. Shanxi Statistics Yearbook of 2016. Shanxi Statistical Bureau: Shanxi, China, 2016.

35. GUAN X., LI W. Cause Analysis on Economic Benefits Decline of China's Coal Industry. Coal Engineering, 47 (1), 136, 2015.

36. KENNEDY P. A Guide to Econometrics 2. MIT press. 2003.

37. SCHWERT G. Effects of model specification on tests for unit roots in macroeconomic data. Journal of Monetary Economics, 20 (1), 73, 1987.

38. ZHANG X. Econometrics Software Eviews User Guide. Nankai University Press, 2004.

39. XU L. Analysis and Prediction of Influencing Factors of Carbon Emissions in Shanxi Province in the Process of Urbanization. Tianjin University, 2014. 
40. LV X., QIU F., MA S. Decomposition Research about the Carbon Emissions of Shanxi Based on LMDI. World Regional Studies, 21 (1), 168, 2012.

41. GENG Y., TIAN M., ZHU Q., ZHANG J., PENG C. Quantification of provincial-level carbon emissions from energy consumption in China. Renewable and Sustainable Energy Reviews, 15 (8), 3658, 2011.

42. ZHANG Y. Shanxi's Energy Structure Adjustment and Coal Transformation in Low-Carbon Age. Energy of China, 36 (3), 40, 2014. 
